\title{
South West Region senior registrar jamborees
}

\author{
Christopher Vassilas, Lecturer, Department of Mental Health, University of Bristol, \\ Bristol BS2 8DZ; and Michael METCALFE, Senior Registrar, Bristol General \\ Hospital, Bristol BS1 6SX
}

Trainees are often called upon to organise educational events. We hope that our experience will be helpful and that some of the lessons we have learnt will be of use to others.

The South-West Region is one of the most geographically dispersed in the country. There are two post-graduate centres, based at the Universities of Bristol and Exeter. Twelve years ago, Professor $\mathbf{H}$. G. Morgan, who was the senior registrar tutor for the Avon rotation suggested that there should be twice yearly meetings for all the senior registrars in the South West Region; trainees would present papers, and the consultants from the region would be invited to attend. For the last 12 years, without a break, these senior registrar jamborees have taken place.

The first 18 jamborees were held alternatively in Exeter and Bristol. However, three years ago a decision was made to try and revitalise the jamborees and the rest of the article will focus on the efforts made to carry this out.

\section{The new model jamboree}

Generally higher training in psychiatry provides good clinical experience; the jamborees were seen as a way that other issues, particularly those to do with research, could be looked at more closely. At the same time, there was a feeling that it would be useful to try and integrate the senior registrars and consultants more closely. Those were the aims. How did we approach the problem?

The topic. It was clear that there were many senior registrars with ideas about research who needed to talk these over with those who had had some research experience.

The format. It was decided to hold the jamboree over a whole day with lunch provided by our sponsors. The morning sessions consisted of small groups with each trainee having the opportunity of presenting an outline of a research project he or she wished to carry out. The groups were led by 'experts' who later held research clinics where particular problems, e.g. statistical issues, could be discussed. Following lunch four trainees presented completed research to an audience which now included consultants from throughout the region. After the presentations, the senior registrars left and the consultants stayed to hear one of their colleagues talk about their personal experience of psychiatry.

The venue. The event took place in the large main hall of an old psychiatric hospital.

\section{Lessons}

(a) Choose group co-ordinators carefully. A few trainees felt their projects had not been given a fair airing as the group co-ordinator did not have any particular knowledge of their area of study.

(b) Don't cram in too many presentations. Three papers in an hour will allow justice to be done to each presentation.

(c) Integrate the day. Having a separate consultant-only session does not encourage senior registrars to see themselves as "consultants in waiting". When asked, the consultants were happy for the senior registrars to be in on their talks about professional issues.

(d) Choose a suitable venue. Having a venue outside any of the major conurbations in the South West was a distinct advantage; there were no parking problems and no early morning traffic jams.

A final point: however warm the hospitality, cosy informality is difficult to achieve in the large high ceilinged halls that act as the main rooms in many older psychiatric hospitals.

\section{Speakers and sponsors}

The 20th jamboree, while well received and apparently smooth-running to outsiders, led to several problems:

(a) a non-medical presenter who didn't answer letters or the telephone and who amassed impressive expenses

(b) sponsors who were unhappy on the day because their estimates were exceeded and because they felt their products were underexposed 
(c) organised chaos, resulting from use of several variants of video technology, some more successful than others.

\section{Lessons}

(a) The standards and reliability of non-medical speakers are variable. It is wise to spend some time making sure that your choice will live up to expectations. Doctors are usually dependable and are almost always happy to contribute to the training of future consultants for a nominal fee and reasonable expenses, especially if personal contacts exist. Busy academics are unlikely to accept an invitation out of the blue.

(b) Sponsorship should be taken seriously. It is best to get to know your representatives and then tell them exactly what they will be getting at the event (e.g. position of stand for products, company name on literature). Costs should be carefully calculated and then an overestimate (by 25-50\%) given to sponsors well in advance. They will always be happy with an event which underspends, but not with the reverse.

(c) Camcorders. These are easy to use and give instant feedback; get acquainted with them beforehand.

\section{Let the lecturer do the work}

Both the 21st and 22nd jamborees were successful, but in very different ways. The 21 st was ambitious and elaborate, involving an organising committee of five, all of whom put in a fair amount of hard work, developing vignettes and collecting research instruments for a day on 'Research Techniques in Psychiatry'. The 22nd involved little organisation on our part as it was simply a matter of 'plugging in' to a university teaching programme on 'How to get the best from your personal computer'.

\section{Lessons}

(a) Don't be over-ambitious. Too much hard work takes its toll and invited speakers have often prepared material previously.

(b) Make use of local resources especially when they are well presented and free.

\section{Nearing perfection (?)}

In our current jamborees, senior registrars continue to make presentations of work, but closer supervision of research (as in the 19th jamboree) has now become a separate regular event in the senior registrar training overseen by the University of Bristol's Department of Mental Health.

The 23rd jamboree was problem-free and enjoyed by all, despite having a non-medical speaker and a fair amount of technology. The video workshop on 'Teaching in Small Groups' worked well. We have now moved on to plan the 24th jamboree on 'The Problems of being a Consultant'. Perhaps, after learning our lessons the hard way, we have now got things just about right.

\section{Developing a liaison project in the community}

\section{A. JANe Naismith, Consultant Psychiatrist, Dykebar Hospital, Paisley PA2 7DE}

It is considered valuable for senior registrars to have experience of liaison with other agencies and of setting up and evaluating projects as part of higher training in community psychiatry (Guthrie, Black \& Osborn, 1991; Royal College Of Psychiatrists Working Group, 1990). However, this may not be easy to arrange due to, for example, lack of suitable opportunities and insufficient time for initiating a project and carrying it through. Such projects are often difficult to establish and the trainee may find that a good idea founders on a variety of unexpected problems.

I will report one such experience and suggest guidelines for other trainees trying to set up projects with non-psychiatric agencies.

\section{Details of the project}

Concern had been expressed by social workers in the area about a lack of provision for the mental health needs of people from ethnic minority backgrounds. It was also felt by the local psychiatric team that the level of uptake of services did not reflect that expected given the size of the local ethnic minority population. It was agreed that a support group for young people should be started using existing staffing resources. There would be input from a community worker, a psychiatrist (myself - then a senior registrar), a bi-lingual community worker from family centre and an area social worker. 